\section{Authors' response to Richard Sherlock's commentary}

\author{
A G M Campbell Department of Child Health, \\ University of Aberdeen. \\ R S Duff Department of Pediatrics, Yale \\ University School of Medicine, New Haven, \\ Connecticut, USA
}

Sherlock complains that the 'fundamental weakness' in our article is our 'unwillingness' to state criteria which distinguish those infants who must be treated from those for whom we would consider the withholding or withdrawal of life-sustaining treatment. Most doctors will know what we mean but we accept that some clarification may be necessary for non-medical readers.

We have assumed always that the vast majority of children with handicapping abnormalities or diseases must be treated. With rare exceptions doctors and parents will agree on the appropriate course of action. In our view the most important medical criterion is the degree of abnormality, disease or damage to the central nervous system, especially the brain. If there is little or no prospect of brain function sufficient to allow a personal life of meaning and quality or no potential for development in harmony with Fletcher's 'indicators of humanhood', 1 non-treatment seems the prudent course of action. This is consistent with the commonsense views held by most parents, physicians, nurses, social workers, chaplains and others with whom we have been in contact. Specific examples of such problems include infants with anencephaly; hydranencephaly; extreme forms of hydrocephalus especially if complicated by other abnormalities or by CNS infection, and certain chromosome disorders such as Trisomy 13. Infants with fully documented severe brain damage following asphyxia, haemorrhage or infection might also be included in this category. At the present time 'heroic' life-sustaining treatment also seems equally pointless in children with progressive degenerative disease of the brain such as the leukodystrophies; or in the terminal stages of intracranial cancer. In another category there is considerable disagreement about the appropriate course of action. Some of these controversies have been widely publicised. This group of infants would include Trisomy 18; Trisomy 2 I (Down's syndrome) with complications; severe forms of spina bifida; and major multiple congenital abnormalities not necessarily involving the brain. But decisions are not made on technical criteria alone. Before making any decision about appropriate management, a detailed, expert and thoughtful review by families and health professionals of all the pertinent biological and social data is essential. A 'good' choice for treatment might be an infant with spina bifida who is wanted, who can be cared for in the family without excessive $\bar{c}$ or coerced sacrifice and for whom the family's $\stackrel{\triangleright}{\perp}$ caring is loving and voluntary. A 'bad' choice for treatment might be a similar infant but where the $\vec{F}$. parents have little or no capacity to care for their $\delta$ child; where the family does not want to be forced to do what they believe should not be done and $\stackrel{\rho}{\rightarrow}$ where resources to help the child or the family are limited or absent. We believe that the agony of facing up to these difficult and tragic choices confers the best protection on infants and their families from $\triangle$ caprice and the tyranny of sometimes cruel i technology. This approach acknowledges the $\vec{P}$ injustice of biology and the inevitability that some human decisions will also be unjust.

Sherlock indicates that we are likely to respond to his commentary by insisting that as these cases vary so much it will not be possible to provide criteria. We hope that the above comments will help to $\dot{\omega}$ clarify our position, but we believe that it is not for $\vec{A}$ us alone nor for families alone to set rigid criteria for $\vec{A}$ treatment or non-treatment. Once again we $\frac{9}{3}$ emphasise our view that patients (when able), $\vec{c}$ families and health professionals (physicians, nurses, $\mathbb{D}$ social workers), together and usually in that order, $\frac{\vec{D}}{\mathrm{~T}}$ should do this instance by instance. This policy 3 implies trust in people. We recognise that a few people may be unworthy of trust but is it not both illogical and unjust to support a policy based on mistrust ? Surely we can recognize and deal with the exceptions. Like colleagues everywhere, we honoury. apparently good choices and challenge apparent 1 bad ones.

A final reason for Sherlock to insist on criteria is a legal one. We do not consider ourselves above the $\stackrel{\square}{\perp}$ law, but we are not concerned primarily with the $\vec{\overrightarrow{ }}$ law. We hope that we and thousands like us are not $\frac{3}{3}$ violating any laws that make sense. It is generally admitted that the law has difficulty in keeping pace with modern medical technology. Legal scholars have warned us that the law is too insensitive to unique human conditions to be of much use in deciding care in particular situations.

We are taken to task for not dealing with a o 'second crucial issue'. Sherlock asks why this proposed policy should not be adopted for older 의 persons in similar situations. Our article was about $D$ infants and children because we work with infants and children, but Sherlock is right. Such a policy N should be applied to others because it is probably o the most caring policy generally. No doubt many $N$ people do just that and always have done. ${ }^{2}$ Indeed, earlier studies of adult patients and their families 0 prompted the approach we outlined for infants. ${ }^{3}$

We do not believe that we support a 'policy of death'-this is emotive hyperbole. We acknowledge $\stackrel{\oplus}{\rightarrow}$ that we sometimes support a choice for death 0 despite some small irreducible uncertainty about the rightness of this choice. We do this because our $\stackrel{\mathbb{Q}}{\stackrel{D}{ }}$ larger task is to help people cope with their lives. In $\underset{\mathbb{Q}}{Q}$ 
this, life may be defended or surrendered. While Sherlock, Ramsey ${ }^{4}$ and others may peck at the details of our policy we believe it is time they acknowledged that patients, families and the public usually want and expect a balance of 'aspirational' heroism to overcome disease and death and 'humble' heroism which accepts defeat. ${ }^{5}$ Modern medical technology requires that choices be made. Decentralised decision making such as we propose probably is superior because it is protective of man's most cherished values. When dogma or rules that are too closely drawn are used as the determinants of decisions, harm will result because the uniqueness of individuals, families and their highly valued intimate retationships cannot be taken into account, much less enhanced.

We believe that our proposed policy is coherent and sensible. It meets most (but not all) objections. We believe that it is tenable in the opinion of those who grasp the larger bio-social picture in patient $\frac{c}{3}$ care, a view we suspect that Sherlock, Ramsey and $\frac{\Phi}{\propto}$ others do not consistently reflect-at least as we seem it.

\section{References}

${ }^{1}$ Fletcher, J (1972) Indicators of humanhood: a tentative profile of man. Hastings center report, 2, I-4,

${ }^{2}$ Brown, N K and Thompson, D J (1979), Non-treatment? of fever in extended care facilities. New England 2 journal of medicine, 300, 1246-1250.

${ }^{3}$ Duff, R S and Hollingshead, A B (1968), Sickness and society, New York: Harper and Row.

${ }^{4}$ Ramsey, P (1978), Ethics at the edges of Life. Medical ${ }_{\vec{\omega}}$ and legal intersections. New Haven and London: Yale University Press.

${ }^{5}$ Preston, $\mathrm{R}$ The dilemmas of care: nursing and social adaptation to the deformed, the disabled and thecr aged. New York: Elsevier. In Press. 